\title{
Maturation of Renal Tubular Transport of Digoxin
}

\author{
MORDECHAI ALADJEM, ${ }^{(12)}$ CHAIM KAPLINSKY, NORMAL WOLFISH, YOSSEF LAUFER, AND \\ HILLEL HALKIN \\ Pediatric Nephrologv and Clinical Pharmacologv Units, The Chaim Sheba Medical Center. Tel-A viv University \\ Sackler School of Medicine, Tel-Hashomer, Israel.
}

\begin{abstract}
Summary
Previous data have suggested an age-related increase in renal tubular secretion of digoxin in infants and children receiving longterm digoxin therapy. This phenomenon could be the result of a maturational process or secondary to chronic substrate stimulation. To investigate this question, two groups of 2-week-old paired littermate rats received intraperitoneal injections of either digoxin or an equal volume of normal saline (control) on alternate days until sacrificed at 4,6 , and 8 wk of age. An additional group of 12wk-old rats were studied as controls. ${ }^{125}$ I-labeled digoxin uptake was measured in renal cortical slices as the $\mathrm{cPM} / \mathrm{mg}$ wet tissue slice/medium ratio (S/M). Both digoxin-treated and control rats demonstrated significant age-related increments in digoxin uptake. $S / M$ ratios at $4,6,8$, and 12 wk in the control group were 1.34 $\pm 0.06,1.39 \pm 0.14,1.62 \pm 0.18$ and $1.93 \pm 0.23$, respectively (mean \pm S.D. $)(r=0.81 ; P<0.001) . S / M$ ratios in the digoxintreated animals at 4,6 , and 8 wk were $1.28 \pm 0.16,1.33 \pm 0.09$, and $1.52 \pm 0.23$, respectively $(r=0.50 ; P<0.025)$, but did not differ significantly at each age from those in the control group. ${ }^{125}$ I uptake was significantly reduced by both dinitrophenol and sodium azide, as well as by a $100 \%$ nitrogen atmosphere.

These results indicate that renal tubular transport of digoxin is an age-related energy dependent process which probably is not subject to substrate stimulation.
\end{abstract}

\section{Speculation}

An age-dependent increase in renal digoxin excretion exists in treated infants and children. This augmentation is due to nonspecific renal maturational phenomena and not to specific substrateinduced tubular transport.

The renal excretion of digoxin was considered to be due mainly to glomerular filtration (2) until Steiness (9) demonstrated that as much as $50 \%$ of the total excretion could be attributed to net tubular secretion. While examining the pharmacokinetics of digoxin in chronically treated infants and children. Halkin et al. (5) demonstrated higher $\mathrm{Cdig} / \mathrm{Ccr}$ ratios in older children than in infants and neonates. These observations could have been explained by maturation of renal tubular transport $(6,10)$, either associated with or independent of chronic substrate stimulation. The aim of this study was to dissociate these two factors, namely maturation versus substrate stimulation, and to investigate in vitro the relative contribution of each to the increasing ability of the developing kidney to excrete digoxin.

\section{MATERIALS AND METHODS}

Paired 2-wk-old littermate Charles River rats received intraperitoneal injections of either digoxin $(0.05 \mathrm{mg} / \mathrm{kg}$ body weight $)$ or an equal volume of normal saline on alternate days until being sacrificed by cervical dislocation at 4, 6, and 8 wk of age. Each age group consisted of seven digoxin-treated rats and seven controls. An additional group of seven 12-wk-old rats was studied as controls. Digoxin and saline injection was withheld 3 days before sacrifice. Kidneys were immediately removed and washed in cold saline. Renal cortical slices, approximately $0.4 \mathrm{~mm}$ thick, were prepared freehand and were placed in incubation beakers containing $5 \mathrm{ml}$ of Cross and Taggart solution (1), digoxin (2.5 ng/ $\mathrm{ml}$ ) (Lanoxin; Wellcome) and $100 \mu 1^{125} \mathrm{I}$-labeled digoxin (Diagnostic Products Corp.) Preliminary experiments showed that the optimal time of digoxin uptake occurred when tissue was incubated for $90 \mathrm{~min}$ [slice/medium $(\mathrm{S} / \mathrm{M})$ ratio, $60 \mathrm{~min}$. $1.63 \pm 0.34$; $90 \mathrm{~min}, 1.89 \pm 0.26 ; 120 \mathrm{~min}, 1.49 \pm 0.31(n=6)]$. After $90 \mathrm{~min}$ incubation under flowing $95 \% \mathrm{O}_{2}$ and $5 \% \mathrm{CO}_{2}$, the slices were removed, blotted on Whatman paper, and weighed. An aliquot of approximately $\mathrm{l} \mathrm{ml}$ of the medium was removed from each beaker for counting. Slice (s) and medium $(M)$ radioactivity was counted in a gamma scintillation counter, and the $S / M \mathrm{cpm} / \mathrm{mg}$ wet weight ratio (the estimate of tissue digoxin uptake) was calculated. The effect of metabolic blockers on digoxin uptake was studied in kidney tissue obtained from nine 12-wk-old rats by the addition of either $4 \times 10^{-4} \mathrm{M}$ DNP or $6.75 \times 10^{-3}$ sodium azide or by incubating in a $100 \%$ nitrogen atmosphere. The effect of dinitrophenol (DNP) or 100\% nitrogen atmosphere on water distribution was determined by incubating the slice tissues for $90 \mathrm{~min}$ in the Cross and Taggart solution containing $\left[\right.$ carboxyl- $\left.{ }^{14} \mathrm{C}\right]$ inulin $(\mathrm{New}$ England Nuclear). At the end of the incubation period, the tissues were blotted, weighed, and dried at $95^{\circ} \mathrm{C}$ until they had reached a constant weight. The dried tissues were extracted with $0.1 \mathrm{~N}$ nitric acid for $48 \mathrm{hr}$, and inulin concentration was determined (liquid scintillation spectrometry). Data are expressed as the mean \pm 1 S.D. Data from simultaneous studies were compared by the unpaired Student $t$ test.

\section{RESULTS}

Both control and digoxin-treated rats manifested gradual agerelated increases in digoxin uptake by the kidney slices.

The ratios observed in the control animals were $1.34 \pm 0.06$ $1.39 \pm 0.14,1.62 \pm 0.18$, and $1.93 \pm 0.23(n=7$ for each group $)$ for the four age groups, respectively $(r=0.81 ; P<0.001)$ (Table 1). A similar age-related increase in $S / M$ ratio was observed in the digoxin-treated rats $[1.28 \pm 0.16,1.33 \pm 0.09$, and $1.52 \pm 0.23$ $(n=7$ for each age group) $(r=0.5 ; P<0.025)$ (Table 1)]. No further increase in $S / M$ ratio was observed in the digoxin-treated rats when compared with the control- (saline) treated group at either 4,6 , or 8 wk (Table 1).

Metabolic blockade at 12 wk of age produced a significant reduction in digoxin uptake ( $\mathrm{S} / \mathrm{M}$ ratio) in kidney slices (Table 2 ) from $1.93 \pm 0.23$ in the control to $1.34 \pm 0.18$ with DNP and 1.30 \pm 0.15 with sodium azide $(P<0.001)$. When $100 \%$ nitrogen replaced oxygen in the incubation atmosphere, $\mathrm{S} / \mathrm{M}$ ratios fell to $1.28 \pm 0.17(n=9$ in each group) $(P<0.001)$. The magnitude of reduction of digoxin uptake was similar with DNP, sodium azide, and $100 \%$ nitrogen.

The addition of DNP when compared to control experiments resulted in a small, however, significant $(P<0.05)$ increase in both total tissue $(6.3 \pm 1.7 \% ; n=6)$ and intracellular water $(6.9$ 
Table 1. Comparison of digoxin uptake ( $S / M$ ratio) in control and digoxin-treated rats $(n=7$ in each group)

\begin{tabular}{ccc}
\hline Age (wk) & Control group & Digoxin-treated group \\
\hline 4 & $1.34 \pm 0.06$ & $1.28 \pm 0.16$ \\
6 & $1.39 \pm 0.14$ & $1.33 \pm 0.09$ \\
8 & $1.62 \pm 0.18$ & $1.52 \pm 0.23$ \\
10 & $1.93 \pm 0.23$ & Not done \\
\hline
\end{tabular}

Table 2. The effect of metabolic blockade (DNP, sodium azide, and $\left.100 \% N_{2}\right)$ on digoxin uptake ( $S / M$ ratio)

\begin{tabular}{cc}
\hline Group & S/M ratio \\
\hline Control & $1.93 \pm 0.23$ \\
DNP & $1.34 \pm 0.18$ \\
$\mathrm{Na}^{+}$azide & $1.30 \pm 0.15$ \\
$100 \% \mathrm{~N}_{2}$ & $1.28 \pm 0.17$ \\
\hline
\end{tabular}

$\pm 1.9 \% ; n=6$ ). Similarly, when slices were incubated in $100 \%$ nitrogen atmosphere, total tissue water increased by $5.4 \pm 1.2 \%$ $(n=6)$, and intracellular water increased by $5.7 \pm 1.3 \%(n=6)$ $(P<0.05)$.

\section{DISCUSSION}

Maturation of glomerular and tubular function is a well-described process of development during early life (3) which can be augmented nonspecifically by dietary manipulation (4). Stimulation of individual tubular transport mechanisms has been demonstrated by Hirsh and Hook (6) by the administration of specifically related substances.

The urinary excretion of digoxin occurs by glomerular filtration. The existence of a tubular transport mechanism of digoxin in man, accounting for $50 \%$ of the total renal digoxin clearance, has been found by Steiness (9). Subsequently, Roman and Kauker (8) were able to demonstrate a transtubular digoxin influx of $41.9 \%$ in the rat. Halkin et al. (5) have studied the pharmacokinetics of digoxin in chronically treated infants and children. Recalculation of their data has shown an age-related increment of Cdig/Ccreat ratios from neonates to children. Their studies could not resolve whether the increase in renal tubular secretion of digoxin was simply the result of maturational phenomena or whether specific substrate induction by chronic digoxin administration was the responsible factor.

Our data demonstrate an age-related progressive and gradual increase in digoxin uptake by kidney slices in both saline- and digoxin-treated groups. No difference in digoxin uptake was observed between these two groups, implying a lack of specific substrate-induced stimulation by chronic digoxin administration.
Transtubular influx is fundamentally a two-step transport process, blood to tubular cell and tubular cell to lumen. Inasmuch as the intraluminal pool is largely nonfunctional in the model used (7) and the extracellular digoxin concentration is due to a diffusional process alone, the $\mathrm{S} / \mathrm{M}$ ratios above unity probably represent a cellular accumulation of the drug. The age-related increase in $\mathbf{S} / \mathbf{M}$ digoxin ratios may result in a more favorable cell-tolumen gradient, thus increasing tubular secretion of digoxin with age. The transport mechanism, although subject to maturational changes, could not be stimulated by the administration of digoxin. possibly because the dose was too low as dictated by pharmacologic considerations.

The reduction in the $\mathrm{S} / \mathrm{M}$ digoxin ratios induced by the metabolic blockers was significantly higher than the fluid shifts observed when slices were incubated with DNP or in a $100 \%$ nitrogen atmosphere. Thus, it seems that digoxin transport is an active, energy-dependent process. Alternatively, a high degree of tissue binding affected by metabolic blockers can not be ruled out.

We suggest that the age-dependent incremental augmentation is digoxin transport in the rat is due to nonspecific renal maturation. This mechanism appears not to be due to substrate induction when pharmacologic doses of digoxin are used. This transport process is energy dependent. Although clinical extrapolation is tenuous, our data may contribute to the evaluation of the agerelated increase in transtubular transport of digoxin observed in children (5).

\section{REFERENCES AND NOTES}

1. Cross. R. J., and Taggart. V. J.: Renal tubular transport: accumulation of $p$ aminohippurate by rat kidney slices. Am. J. Physiol.. 101: 181 (1950).

2. Doherty, J. E., Ferrel. C. B.. Towkin. E. J.: Localization of the renal excretion of tritiated digoxin. Am. J. Med. Sci., 258: 181 (1969).

3. Edelmann, C. M.. Jr.: Maturation of the Neonatal Kidney. In: E. Becker: Proc Third Int. Congr. Nephrol., Washington 1966. Vol. 3 (Basel, Karger, 1967).

4. Edelmann, C. M., Jr., and Wolfish, N. M.: Dietary influence on renal maturation in premature infants. Pediatr. Res.. 3: 5 (1969).

5. Halkin. H., Radomsky, M., Millman. P., Almog. S., Blieden, L., and Boichis. H.: Steady state serum concentrations and renal clearance of digoxin in neonates infants and children. Eur. J. Clin. Pharmacol.. 13: 113 (1978).

6. Hirsh, G. H., and Hook, J. B.: Maturation of renal organic acid transport. Substrate stimulation by penicillin and PAH. J. Pharmacol. Exp. Ther.. 17I: 103 (1970).

7. Rennick, B., and Quabbenzann, A. J.: Renal tubular excretion of drugs: proximal tubule and metabolism. In: J. W. Fisher, E. J. Cafruny: Renal Pharmacology. p. 68 (Appleton-Century-Crofts. New York, 1971).

8. Roman, J. R., and Kauker. L. M.: Renal tubular transport of $\mathrm{H}^{3}$ digoxin in saline diuresis in rats: evaluation by micropuncture. Circ. Res., 38: 115 (1976).

9. Steiness, E.: Renal tubular secretion of digoxin. Circulation, 50: 103 (1974)

10. Zink, M., and Horster. M.: Maturation of diluting capacity in loop of Henle of rat superficial nephrons. Am. J. Physiol., 233: 519 (1977).

11. The authors gratefully acknowledge the assistance of Aliza Eshkol, Ph.D.. in carrying out this research project.

12. Requests for reprints should be addressed to: Dr. M. Aladjem. M.D.. Pediatric Renal Unit. The Chaim Sheba Medical Center. Tel-Hashomer, Israel.

13. Received for publication January $28,1980$.

14. Accepted for publication July $28,1980$. 